\title{
A molecular census of early-life stage scleractinian corals in shallow and mesophotic zones
}

\author{
Derek Soto ${ }^{1,2,3}$ (D) | Stéphane De Palmas ${ }^{1,2,3}$ (D) | Ming-Jay Ho Ho ${ }^{2,4}$ Vianney Denis ${ }^{5}$ (D) | \\ Chaolun Allen Chen ${ }^{2,3,6}$
}

${ }^{1}$ Biodiversity Program, Taiwan International Graduate Program, Academia Sinica and National Taiwan Normal University, Taipei, Taiwan

${ }^{2}$ Biodiversity Research Center, Academia Sinica, Taipei, Taiwan

${ }^{3}$ Department of Life Science, National Taiwan Normal University, Taipei, Taiwan

${ }^{4}$ Green Island Marine Research Station, Academia Sinica, Ludao, Taitung County, Taiwan

${ }^{5}$ Institute of Oceanography, National Taiwan University, Taipei, Taiwan

${ }^{6}$ Department of Life Science, Tung Hai University, Taichung, Taiwan

\section{Correspondence}

Chaolun Allen Chen, Biodiversity Research Center, Academia Sinica, Taipei, Taiwan.

Email: cac@gate.sinica.edu.tw

\section{Funding information}

This research was funded by two Taiwan Ministry of Science and Technology (MOST) grants, MOST 103-2621-B-001-004-MY3 to CAC and MOST 108-2611-M-002-013 to VD. DS and SdP were recipients of the Taiwan International Graduate Program Fellowship during 2015-2018 and were funded by CREEG laboratory and CAC during the study period. The funders had no role in study design, data collection and analysis, decision to publish, or preparation of the manuscript.

\begin{abstract}
The decline of coral reefs has fueled interest in determining whether mesophotic reefs can shield against disturbances and help replenish deteriorated shallower reefs. In this study, we characterized spatial (horizontal and vertical) and seasonal patterns of diversity in coral recruits from Dabaisha and Guiwan reefs at Ludao, Taiwan. Concrete blocks supporting terra-cotta tiles were placed at shallow $(15 \mathrm{~m})$ and mesophotic (40m) depths, during 2016-2018. Half of the tiles were retrieved and replaced biannually over three 6-month surveys (short-term); the remainder retrieved at the end of the 18-month (long-term) survey. 451 recruits were located using fluorescent censusing and identified by DNA barcoding. Barcoding the mitochondrial cytochrome oxidase I (COI) gene resulted in 17 molecular operational taxonomic units (MOTUs). To obtain taxonomic resolution to the generic level, Pocillopora were phylotyped using the mitochondrial open reading frame (ORF), resolving eight MOTUs. Acropora, Isopora, and Montipora recruits were identified by the nuclear PaxC intron, yielding ten MOTUs. Overall, 35 MOTUs were generated and were comprised primarily of Pocillopora and, in fewer numbers, Acropora, Isopora, Pavona, Montipora, Stylophora, among others. $40 \%$ of MOTUs recruited solely within mesophotic reefs while $20 \%$ were shared by both depth zones. MOTUs recruiting across a broad depth distribution appear consistent with the hypothesis of mesophotic reefs acting as a refuge for shallow-water coral reefs. In contrast, Acropora and Isopora MOTUs were structured across depth zones representing an exception to this hypothesis. This research provides an imperative assessment of coral recruitment in understudied mesophotic reefs and imparts insight into the refuge hypothesis.
\end{abstract}

\section{KEYWORDS}

barcoding, diversity, recruitment, refuge, settlement, Taiwan 


\section{1 | BACKGROUND}

Climate change and other human disturbances have propelled an ongoing decline in coral reefs worldwide, and the outlook of reefs remains bleak (Hoegh-Guldberg et al., 2018; Hughes et al., 2017; Van Hooidonk et al., 2016). Mesophotic coral ecosystems (MCEs)-coral reefs between 30 and $150 \mathrm{~m}$-may shelter against disturbances which affect shallower reefs $(<30 \mathrm{~m})$ and may propagate larvae to recruit on impacted shallow reef ecosystems (Baird et al., 2018; Bongaerts et al., 2010; Bongaerts \& Smith, 2019). Reproduction in corals is induced by environmental cues, such as the synergic properties of increasing light and temperature (reviewed in Harrison (2011)). Because these signals attenuate with depth (Kahng et al., 2019), it is plausible that patterns of recruitment in mesophotic corals may contrast from corals in shallow reefs (Prasetia et al., 2017; Shlesinger et al., 2018). Most mesophotic corals studied to date (9 of 11) have exhibited reduced fecundity and gamete size compared to shallowwater conspecifics, resulting in diminished larval supply (Eyal-Shaham et al., 2016; Holstein et al., 2016; Prasetia et al., 2016, 2017; Shlesinger et al., 2018; Smith et al., 2016). Studies examining genetic connectivity in Montastraea cavernosa (Brazeau et al., 2013; Eckert et al., 2019; Serrano et al., 2014), Porites astreoides (Serrano et al., 2016), and Agaricia fragilis (Bongaerts et al., 2017) reveal population structures partitioned across shallow and deep zones, indicating that vertical genetic exchange is restricted. In contrast, similar analyses in Stephanocoenia intersepta (Bongaerts et al., 2017), Agaricia lamarcki (Hammerman et al., 2018), and Pocillopora verrucosa (de Palmas, 2020) support well-mixed cohorts. Interpreted together, these results suggest that larval exchange across vertical gradients is likely locationand/or species-specific.

Artificial units of recruitment (AURs) have been employed by researchers to assess coral recruitment for more than 100 years (Mundy, 2000), and their application to collect and study recruits has seen widespread use (Field et al., 2007; Hill \& Wilkinson, 2004). Yet, the availability of research targeting recruitment decreases inversely with depth, constrained by the technical challenges associated with working beyond the recreational scuba depth limit. Historically, few studies have examined patterns of recruitment at depths beyond 30m (Bak \& Engel, 1979; Birkeland, 1977; Birkeland et al., 1981; Hughes \& Tanner, 2000; Rogers et al., 1984; Vermeij et al., 2011). As of 2017 , only $1 \%$ of research targeting MCEs had examined recruitment (Turner et al., 2017); however, improved availability of diving and ROV technology and the development of new methods to study MCEs are accelerating this research. For example, Turner et al. (2018), innovated an approach to examine patterns of recruitment at $40 \mathrm{~m}$ depth in Western Australia which foregoes diving. Also, Kramer et al. (2019) used technical diving to describe recruitment dynamics at 50m depth in the Red Sea. Albelda et al. (2020) used conventional scuba to compare juvenile and adult assemblages down to $40 \mathrm{~m}$ depth in the Philippines. Despite recent progress, our knowledge of recruitment in MCEs remains limited and many geographic areas have never been studied, emphasizing the need for more research.
Another challenging aspect of studying the early-life history of corals lies in locating small recruits and identifying them based on few useful morphological characters (Green \& Edmunds, 2011). During settlement, spats metamorphose into their benthic life stage and begin accretion of the corallite matrix (Gilis et al., 2014), on which discrimination of microstructural characters is based (Budd \& Stolarski, 2011). Fluorescence has proven useful for locating and identifying corals during this developmental stage (Baird et al., 2006; Eyal et al., 2015; Hsu et al., 2014; Roth et al., 2013); nevertheless, identification of recruits based on morphological traits is mainly limited to the family level (Babcock et al., 2003; Green \& Edmunds, 2011; Nozawa et al., 2013). This limitation is particularly important in locations where diversity is high and traits converge between confamiliar taxa (Baird \& Babcock, 2000), such as the Indo-Pacific. An inability to identify recruits complicates ecological assessments and hinders our ability to deduce the outlook of threatened coral communities (O'Cain et al., 2019), particularly when confamiliar species fulfill divergent functional roles within an ecosystem (Denis et al., 2017). Therefore, leveraging molecular typing toward improving the taxonomic resolution of early-life stage communities (Hsu et al., 2014; O'Cain et al., 2019; Shearer \& Coffroth, 2006) can yield new insights.

This study details a census and comparison of coral recruitment in shallow and mesophotic reef communities at Ludao, an island off southwestern Taiwan. Shallow and mesophotic communities at Ludao have been shown to possess distinctive communities, despite similarities in coral assemblages (Lin \& Denis, 2019). In the past, assessments of recruitment in Taiwan were conducted above 15m (Edmunds et al., 2014; Ho \& Dai, 2014; Nozawa et al., 2013; Soong et al., 2003) and all have identified recruits morphologically, except Hsu et al. (2014) which identified recruits by barcoding. Here, we employ technical scuba diving and a sampling design in which tiles are fixed to blocks to survey recruitment within shallow and mesophotic zones. We censused recruits with the aid of fluorescent and white light and then barcoded their DNA using three molecular markers to identify recruits and generate molecular operational taxonomic units (MOTUs).

\section{2 | MATERIALS AND METHODS}

Recruitment was surveyed off the coast of Ludao Island, situated $33 \mathrm{~km}$ southeast of Taiwan, during April 2017-October 2018. Two shallow (14-16 m; hereafter 15m) and two mesophotic sites (38-42 m; hereafter $40 \mathrm{~m}$ ) were selected according to habitat composition, favorable wind, wave and current conditions, and accessibility: Guiwan $15 \mathrm{~m}\left(22^{\circ} 36^{\prime} 35.57^{\prime \prime} \mathrm{N}, 121^{\circ} 28^{\prime} 57.10^{\prime \prime}\right.$ E), Guiwan 40m (22³8'24.59"

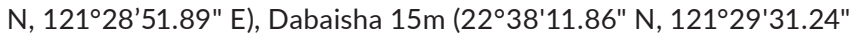
E), and Dabaisha 40m (22³8'09.08" N, 12129'21.44" E). Shallow reefs at Guiwan and Dabaisha consist of fringing reef structures which are subjected to high-energy hydrodynamic transport (Lau et al., 2015). These benthic communities are characterized by arborescent, bushy, and tabular hard corals, clustered octocorals, and 
encrusting actinarians (Lin \& Denis, 2019). MCEs at Guiwan and Dabaisha exhibit limited hard substrates interspersed with sediment and rubble (Denis et al., 2019). Communities at mesophotic sites are denoted by unattached hard corals, bushy and encrusting octocorals, massive sponges, encrusting ascidians, filamentous cyanobacterians, and bushy hydrozoans (Lin \& Denis, 2019).

Artificial units of recruitment (AURs) were constructed from concrete blocks drilled to accept 12 stainless steel concrete sleeve anchors: six on the superior surface and three on each opposing lateral surface (Figure 1a). A labeled terra-cotta tile measuring $12.5 \times 12.5 \times 1 \mathrm{~cm}$ (total surface area $362.5 \mathrm{~cm}^{2} /$ tile) was fastened to each sleeve using a stainless steel washer and nut, resulting in an arrangement of 12 plates per block. Plates were fixed at a height of approximately $7 \mathrm{~cm}$ from the face of the block. Six seasonal and six long-term tiles were distributed between the superior and lateral faces of the block using a Latin square design, producing an arrangement of three vertical long-term tiles, three vertical seasonal tiles, three horizontal long-term tiles, and three horizontal seasonal tiles. AURs were deployed during 4-8 April 2017, a few days prior to the mass coral spawning date, expected between 1 and 11 days after the full moon (full moon: 11 April 2017). In total, 20 AURs were deployed during the survey: five AURs were deployed at shallow, and upper mesophotic zones at Guiwan and Dabaisha (Figure 1b), respectively. Seasonal tiles were deployed and retrieved at three 6-month intervals [Season 1 (S1): April-October 2017, Season 2 (S2): October 2017-April 2018, Season 3 (S3): April-October 2018]. Long-term (LT) tiles remained in place throughout and were retrieved at the end of the study period (April 2017-October 2018). Seasonal sampling consisted of 30 tiles per depth, per site, per season. Retrieved tiles were organized in numbered resealable bags and maintained in bins filled with circulating seawater to preserve them until processing. Coral recruits, defined as individuals that successfully settled and survived until the time of collection, were detected by visually inspecting tiles under fluorescent light, according to the methodology described in Hsu et al. (2014). Spats were located and photographed under fluorescent blue light (Night Sea BB67), filtered through longpass barrier (>500 $\mathrm{nm}$ wavelength) filter glasses (Night Sea VG1). An additional survey under white light verified that weakly fluorescent and nonfluorescent spats were collected. All tile surfaces: top, bottom, and four sides, were inspected for recruits. Spats were removed by scraping with a small chisel and preserved in tagged vials containing $99 \%$ ethanol. Tiles and remaining assemblages were tagged, bleached, and dried for storage as vouchers.

DNA was extracted using DNEasy Blood and Tissue kits (Qiagen) following the manufacturer's instructions but with slight modifications to increase DNA yield. Samples were incubated overnight in lysis buffer/proteinase $\mathrm{K}$ solution, and an additional centrifugation was performed $(16,000 \mathrm{~g}$ for $3 \mathrm{~min}$ ) before DNA elution in order to completely dry the filter column. DNA concentration and purity were verified using a NanoDrop Spectrophotometer (Thermo Scientific). DNA was serially diluted to achieve a concentration approximating $10 \mathrm{ng} / \mathrm{ml}$. PCR was amplified using $15 \mu \mathrm{l}$ Taq $2 X$ Master Mix (Amplicon) diluted to achieve a $30 \mu$ total reaction volume. Coral spat DNA was phylotyped using primers which amplify the mitochondrial cytochrome oxidase subunit I (COI) region, commonly used to differentiate metazoan invertebrates (Folmer et al., 1994). COI primers: LCO1490: 5'-GGT CAA CAA ATC ATA AAG ATA TTG G-3' and HCO2198: 5'-TAA ACT TCA GGG TGA CCA AAA AAT CA$3^{\prime}$. Thermal cycling for $\mathrm{CO}$ entailed an initial heating at $95^{\circ} \mathrm{C}$ for $3 \mathrm{~min}$ followed by $30 \mathrm{cycles}$ at $95^{\circ} \mathrm{C}$ for $60 \mathrm{~s}, 45^{\circ} \mathrm{C}$ for $60 \mathrm{~s}$, and $72^{\circ} \mathrm{C}$ for $90 \mathrm{~s}$, and a final elongation step of $7 \mathrm{~min}$ at $72^{\circ} \mathrm{C}$. Spats identified as Pocilloporidae were further resolved using the mitochondrial open reading frame (ORF) region as described in Chen et al. (2008). ORF primers: FATP6.1:5'-TTT GGG SAT TCG TTT AGC AG-3' and RORF: 5'-SCC AAT ATG TTA AAC ASC ATG TCA-3'. Thermal cycling for $O R F$ comprised an initial heating at $94^{\circ} \mathrm{C}$ for $3 \mathrm{~min}$ followed by 40 cycles at $94^{\circ} \mathrm{C}$ for $30 \mathrm{~s}, 53^{\circ} \mathrm{C}$ for $30 \mathrm{~s}$, and $72^{\circ} \mathrm{C}$ for $90 \mathrm{~s}$, and a final elongation step of $7 \mathrm{~min}$ at $72^{\circ} \mathrm{C}$. Spats placed by $\mathrm{CO}$ within the Acroporidae were subjected to additional PCR using the nuclear PaxC 46/47 intron (van Oppen et al., 2011). PaxC primers: PaxC_intron-FP1: 5'-TCC AGA GCA GTT AGA GAT GCT GG-3' and PaxC_ intron-RP1: 5'-GGC GAT TTG AGA ACC AAA CCT GTA-3'. PCR protocol for $\mathrm{PaxC}$ consisted of a $95^{\circ} \mathrm{C}$ denaturation step for $3 \mathrm{~min}$, followed by 5 cycles of $30 \mathrm{~s}$ at $94^{\circ} \mathrm{C}, 30 \mathrm{~s}$ at $50^{\circ} \mathrm{C}, 1 \mathrm{~min}$ at $72^{\circ} \mathrm{C}$, followed by 26 cycles with an annealing temperature of $56^{\circ} \mathrm{C}$, and a final elongation of $7 \mathrm{~min}$ at $72^{\circ} \mathrm{C}$. Reactions were verified using $2 \%$ agar gel electrophoresis and fluorescent gel staining prior to outsourcing for Sanger sequencing.

Raw forward and reverse sequences were screened by querying the NCBI BLAST database (Megablast) (Altschul et al., 1990), and sequences not matching scleractinian corals were excluded from further analysis. Using UGENE v.1.31 (Okonechnikov et al., 2012), DNA
(A)

FIGURE 1 a. Experimental design. Artificial unit of recruitment (AUR): a concrete block filled with cement for ballast and anchored to the seafloor with a rebar. Each block supports 12 plates: 6 in vertical orientation and 6 in horizontal orientation. Plate shading identifies seasonal and long-term plate placement. b. Schematic of blocks on reef (not to scale)
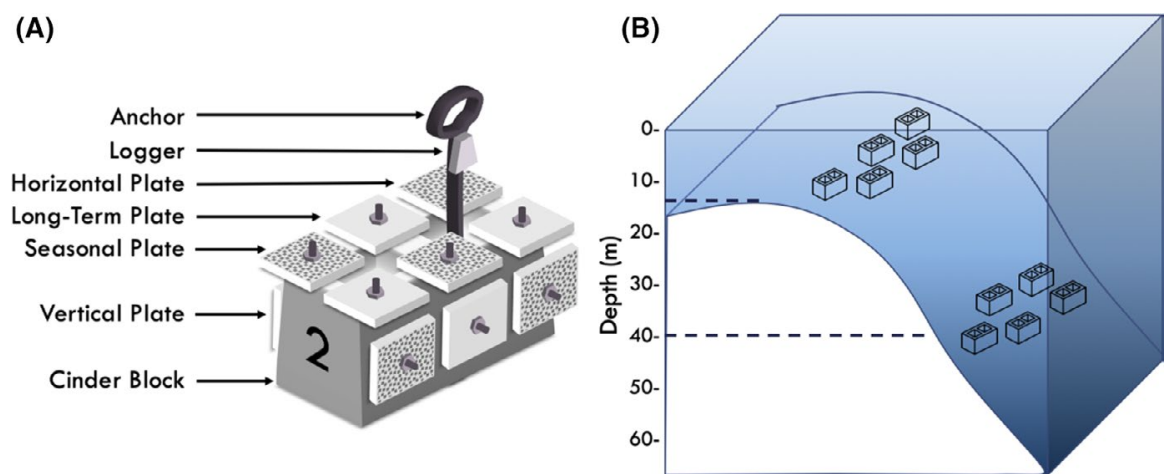
sequences were assembled, and consensus sequences were created from forward and reverse reads and aligned using the MUSCLE algorithm (Edgar, 2004). COI sequences were compared to GenBank sequences of the same marker matching the search terms "scleractinia" (Benson et al., 2005). PHYLIP neighbor-joining trees consisting of sample and reference sequences were generated under the F84 distance matrix model in UGENE (Felsenstein, 2004). Molecular operational taxonomic units were generated using a furthest neighbor clustering algorithm defining MOTUs on 5\% dissimilarity. Sequences identified with $\mathrm{COI}$ as Pocilloporidae underwent additional phylotyping of the ORF region and those identified as Acroporidae were typed with PaxC. PaxC and ORF sequences were aligned with GenBank reference sequences which matched the search terms "acroporidae" and "pocilloporidae," respectively. MOTUs for these markers were assigned following the same protocol used for the $\mathrm{COI}$ marker. Finalized phylogenetic trees were rendered using the interactive Tree of Life (iTOL) (Letunic \& Bork, 2019). Pearson's chisquared tests were performed using the "stats" package in $\mathrm{R}$ version 3.4.2 (R Core Team, 2013).

\section{3 | RESULTS}

We collected 518 coral-like spats and identified 451 coral spats through the combined barcoding of $\mathrm{COI}, \mathrm{ORF}$, and PaxC. Recruitment averaged $19.1 \pm 80.0$ recruits $/ \mathrm{m}^{2}$ throughout the study period. $55.5 \%$ of spats originated from shallow AURs and $44.5 \%$ from mesophotic AURs. $65.3 \%$ of spats recruited on horizontally oriented tiles and $34.7 \%$ recruited on vertically oriented tiles. Sixty-seven samples were excluded from our analysis, representing $7.7 \%$ of the overall collection: 37 specimens phylotyped as nonscleractinian invertebrates, 22 spats for which no PCR product was obtained, or which did not return any matches in BLAST database searches, 5 pocilloporid samples which did not amplify ORF, and 3 acroporid samples which did not amplify PaxC. Recruitment was more abundant during S1 (150 recruits) and S3 (126 recruits), largely exceeding S2 (24 recruits).

Phylogenetic analysis of $\mathrm{COI}$ sequences (Figure 2) distinguished complex and robust clades. We identified 348 Pocilloporidae: 346 Pocillopora spp. and two Stylophora pistillata. Thirty-one recruits were classified as Acroporidae: 17 Isopora spp., nine Acropora spp., four Montipora spp., and a single Astreopora sp. We also collected five Agariicid recruits: four Pavona sp. (I) and another Pavona sp. of a different haplotype (II). Also, two Astrocoeniidae haplotypes: one Stylocoeniella sp. (I) and one Stylocoeniella sp. (II) and three Fungiidae genera were recovered: Lobactis sp., Cycloseris sp., and Sinuorota sp. Poritidae were represented by two individual haplotypes: Porites sp. (I) and Porites sp. (II) Single individuals represented the Dendrophyllidae, Merulinidae, Psammocoridae, and Lobophyllidae families, respectively: Dipsastraea sp., Goniastrea sp., Psammocora sp., and Lobophyllia sp., Leptastreidae sp. is temporarily unclassified (Scleractinia incertae sedis). A single azooxanthellate coral, Dendrophyllia sp., was also identified.
Using the ORF marker, we barcoded 399 samples comprising 346 recruits classified with $\mathrm{COI}$ as Pocillopora, and an additional 53 samples which were unidentifiable with $\mathrm{COI}$ but which amplified with the ORF marker. Additionally, the identities of two recruits typed with $\mathrm{COI}$ as Stylophora pistillata were verified. Phylogenetic analysis of the ORF marker (Figure 2b) identified eight Pocillopora MOTUs. Overall, the most abundant MOTU retrieved in this study was Pocillopora verrucosa, comprising 282 recruits, and representing $62.5 \%$ of all identified recruits and $70 \%$ of all pocilloporids. We also identified 76 Pocillopora grandis, 27 Pocillopora acuta, nine Pocillopora sp. (Type 7), two Pocillopora sp. (Type 2), and three unique taxa: Pocillopora damicornis, Pocillopora sp. (Type 1), and Pocillopora sp. (Type 8).

Thirty recruits typed with $\mathrm{COI}$ as Acropora, Isopora, or Montipora were resolved further with the $\mathrm{PaxC}$ marker and resolved into ten MOTUs (Figure 2c). Isopora sp. (I), likely I. palifera, was the most abundant taxon $(n=14)$, comprising almost half of acroporids found. PaxC genotyping also confirmed three Isopora sp. (II), four Montipora sp. (I), two Acropora sp. (III), two Acropora sp. (IV), two Acropora sp. (V), and four unique MOTUs: Acropora sp. (I), Acropora sp. (VI), Acropora sp. (II), and Montipora sp. (II).

Overall, we identified 35 MOTUs from coral recruits barcoded COI, ORF, and PaxC markers, (Figure 3): 17 MOTUs derived from the COI marker, eight MOTUs were obtained from ORF barcoding, and ten MOTUs from PaxC. 15 MOTUs recruited only within the shallow zone, while 13 were found only in the mesophotic zone and seven MOTUs recruited at both depths (Figure 3). Thirteen MOTUs recruited during S1, 9 MOTUs during S3, and 8 MOTUs in S2. Seasonality $\left(\chi^{2}=152.6, p<.005\right)$, site $\left(\chi^{2}=50.8, p=.03\right)$, and depth $\left(\chi^{2}=88.6, p<.005\right)$ significantly impacted the distribution of MOTUs in this study. When acroporids were excluded, depth $\left(\chi^{2}=65.4, p<.001\right)$, and season $\left(\chi^{2}=123.3, p<.001\right)$ remained significant but sites did not $\left(\chi^{2}=34.2, p=.079\right)$.

\section{4 | DISCUSSION}

We collected and identified 451 recruits, comprising 35 MOTUs and 13 coral families. Many recruits-the smallest of which possessed a diameter of $0.7 \mathrm{~mm}$-were too small to reliably identify morphological characters which would enable identification beyond the family tier. Unidentified samples composed $4 \%$ of our overall collection and reflect a marked improvement compared to a similar study using a high-salt DNA extraction method (9.7\%)(Hsu et al., 2014). At least 328 scleractinian coral species inhabit the reefs of Taiwan and 8 MOTUs identified in this study have been found in previous diversity surveys (Dai \& Horng, 2009a, 2009b; Denis et al., 2015, 2019; de Palmas et al., 2018; Huang et al., 2015). Past synonymization of "Pocillopora damicornis-like" coral morphologies (Poquita-Du et al., 2017; Schmidt-Roach et al., 2014) has obscured the diversity of Pocillopora acuta in previous surveys of Taiwan, explaining its absence in species catalogs. Nevertheless, recent studies have begun addressing this deficiency. Their presence could indicate 


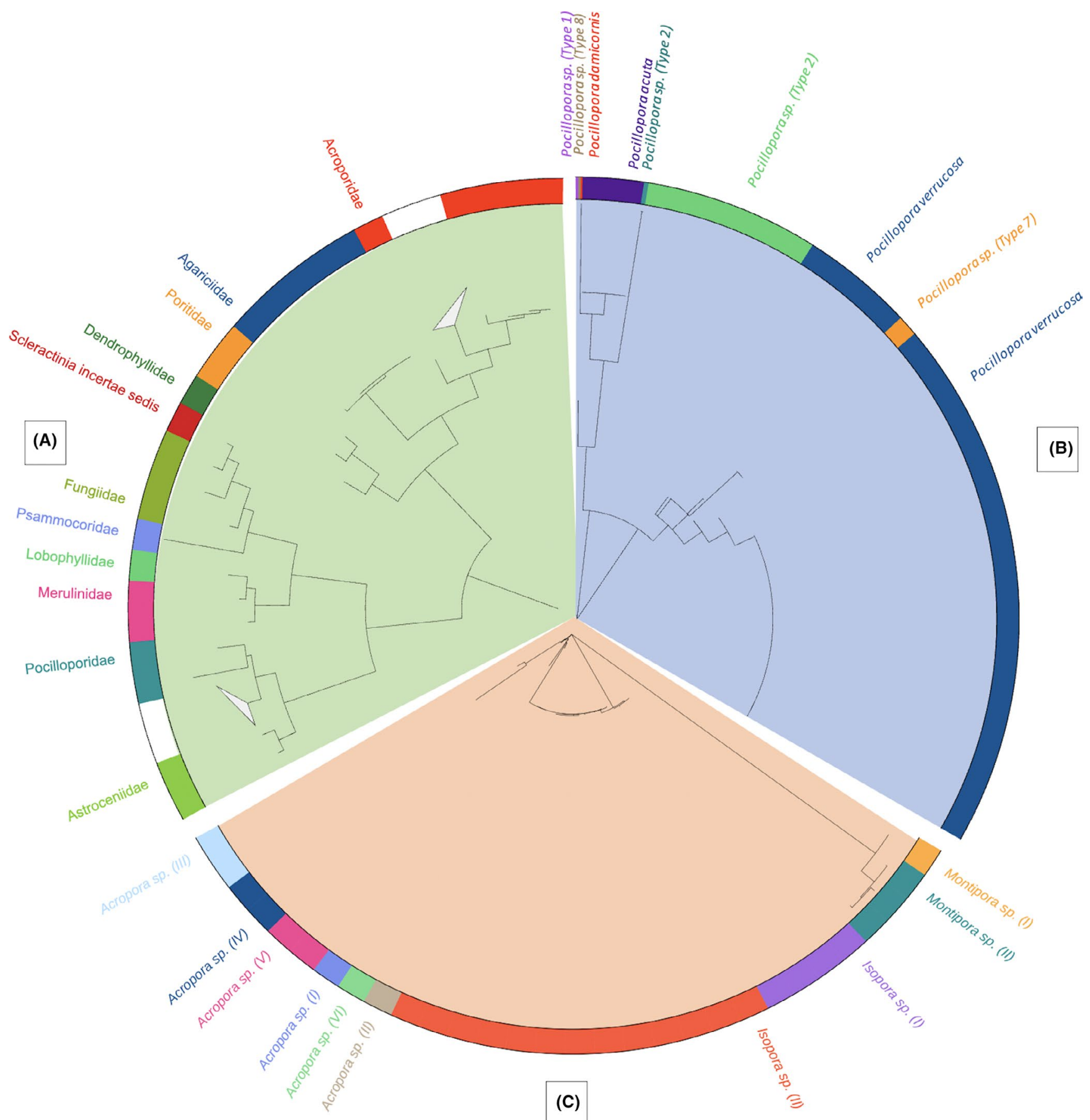

FIGURE 2 Neighbor-joining tree of a. COI, b. ORF, and c. PaxC barcoded recruits. Collapsed branches in a. represent Acropora and Pocillopora, respectively

long-distance larval transport and/or undocumented diversity in Taiwan; however, more intensive surveys are required to verify this inference. Ninety-six scleractinian coral species have been found to inhabit Taiwanese mesophotic reefs to date (Denis et al., 2019), of which our survey found three: $P$. damicornis, $P$. eydouxi, and $P$. verrucosa. Because these species can also be found on shallow reefs, vertical larval transport seems plausible. Denis et al. (2019) also list ten coral species known to inhabit the mesophotic zone exclusively, yet none were identified in our survey.
Pocilloporidae were abundantly represented throughout our study, comprising 401 individuals and nine MOTUs including the Pocillopora and Stylophora genera. This pattern is consistent with other Taiwanese surveys where Pocilloporidae were the most proliferous group (Edmunds et al., 2014; Ho \& Dai, 2014; Hsu et al., 2014; Kuo \& Soong, 2010; Soong et al., 2003). The Pocillopora genus comprised $88 \%$ of overall recruitment but contributed only $27 \%$ of overall MOTUs. Pocillopora is a genus notoriously difficult to identify solely based on morphology and its diversity might be 


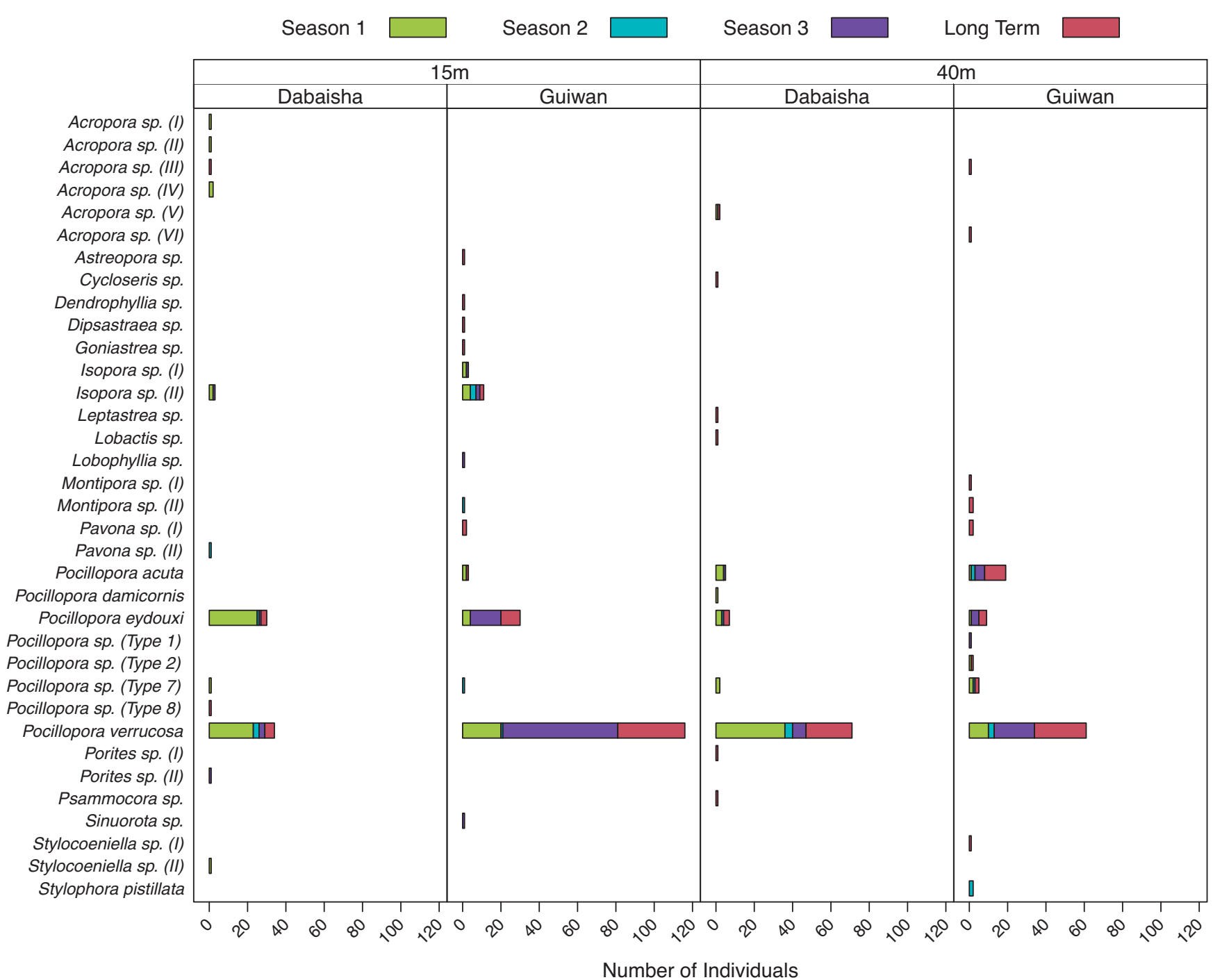

FIGURE 3 Summary of MOTUs generated from barcoded COI, ORF, and PaxC markers, sorted by seasons, sites, and depth zones, in alphabetical order

underestimated when forgoing genetic identification (de Palmas et al., 2018; Soto et al., 2018). For example, the synonymization of "Pocillopora damicornis-like" coral morphologies (Poquita-Du et al., 2017; Schmidt-Roach et al., 2014) has obscured the diversity of Pocillopora acuta in previous surveys of Taiwan. This issue which has only been addressed recently (Mayfield et al., 2018) and may explain the absence of $P$. acuta in older species catalogs but its detection by genetic assays. In Ludao, P. verrucosa exhibits a wide bathymetric distribution and constitutes one of the dominant corals structuring shallow and mesophotic seascapes. In addition, $P$. verrucosa is a functionally competitive species, capable of sustained recruitment (Kayal et al., 2018), explaining its position as the most copious recruiter here.

Acroporidae was the only taxonomic group to exhibit clear bathymetric structuration, and only one MOTU, Acropora sp. (III), was present at both depth zones. At least 90 Acroporidae species are currently documented in Taiwan and this family yielded relatively high richness (11 MOTUs), but low abundance $(n=31)$. Some acroporids are shallow-dwelling and rapid-growing species and exhibit competitive life-history traits (Darling et al., 2012). In a study of northern Taiwan, Acroporidae were the most abundant family in long-term surveys and formed the largest spats, suggesting superior survivorship compared to other families (Ho \& Dai, 2014). Another study in Ludao found vertically structured distribution in acroporid recruitment, recruiting abundantly at $5 \mathrm{~m}$, but not at $15 \mathrm{~m}$, where pocilloporid and poritid recruits dominated instead (Nozawa et al., 2013). It is therefore plausible that greater diversity of Acroporidae may have been captured by surveying shallower. In addition, acroporids are vulnerable to physical disturbances such as storms (Madin, 2005), which have severely impacted local populations (Chen \& Dai, 2004; Kuo et al., 2011, 2012). It is possible that low acroporid coral cover locally (Ribas-Deulofeu et al., 2016) may have led to scarce recruitment in our study, as recruitment in this group is subject to densitydependent effects (Kayal et al., 2015, 2018).

Poritidae were significant recruiters in previous surveys around Taiwan (Edmunds et al., 2014; Ho \& Dai, 2014; Hsu et al., 2014; 
Kuo \& Soong, 2010; Nozawa et al., 2013), but were rare in ours. Massive Indo-Pacific poritids and many merulinids are associated with a stress-resistant life-history strategy characterized by slow growth, long generation times, and sustained recruitment (Darling et al., 2012). However, these types of corals can survive long periods in the absence of recruitment (Hughes \& Tanner, 2000); therefore, low recruitment in those taxa, while unusual, is not entirely uncharacteristic of this type of life history.

The potential for MCEs to reseed shallow reefs may apply to species with wide depth distributions which inhabit both depths (Bongaerts \& Smith, 2019). Of 20 MOTUs found recruiting within the mesophotic zone, 14 (40\%) recruited solely within deeper reefs and only in low abundances. Only seven MOTUs (20\%) recruited at both depth zones and four of these were Pocillopora (Pocillopora sp. (Type 7), P. acuta, P. eydouxi, P.verrucosa). Research supports genetic connectivity in Pocillopora verrucosa across a shallow-mesophotic gradient (de Palmas, 2020), indicating compatibility with the deep reef refuge hypothesis (Bongaerts et al., 2010). Therefore, we hypothesize that the other Pocillopora MOTUs, which recruit at both depth zones, may be genetically connected across this depth gradient as well; however, additional research aimed at discriminating patterns of population genetics is required. Pavona sp. (I) and Montipora sp. (II) also recruited at both depths; however, sparse recruitment limits the interpretation of these patterns. Based on the evidence presented here, the potential for refuge in Ludao is apparent in only a handful of MOTUs; therefore, we emphasize that individual species should be scrutinized prior to generalization to the community level. Nevertheless, connectivity over timescales exceeding this 18-month study period cannot be ruled out, as long-distance dispersal of migrants over ecological timescales (Noreen et al., 2009; van Oppen et al., 2008) or step-wise transgenerational dispersal (Holstein et al., 2015; Vaz et al., 2016) may be sufficient to establish connectivity.

Pelagic larval duration (PLD) varies among coral species and positively correlates with dispersal distance (Shanks et al., 2003). Coral larvae are notoriously poor swimmers and exhibit limited ability to outmaneuver prevailing currents (Hata et al., 2017). Nevertheless, larval traits such as swimming behaviors, lipid content, energy availability, zooxanthellate acquisition, and buoyancy characteristics can profoundly impact dispersal potential (Harii et al., 2002; Richmond, 1987; Shanks, 2009; Szmant \& Meadows, 2006). Pocillopora damicornis planulae are zooxanthellate and swim actively, enabling a long PLD of up to 212 days (Harrigan, 1972). In contrast, its sister species, P. acuta, is characterized by brief PLD, which leads to localized recruitment (Bahr et al., 2020). PLD is a critical trait for estimating connectivity and is available for many fish and other commercially important species; however, the PLDs of many coral species are still unknown. We hypothesize that extensive PLDs in Pocillopora may explain the widespread distribution of this genus in our survey. PLD could be a critical characteristic defining species which can disperse broadly and find refuge, and this possibility should be researched further. The prevalence of traits and/ or behaviors which facilitate dispersal could explain the absence or low abundance of coral taxa restricted to one particular habitat in our experiment.

Reproductive modalities may also influence the dispersal of larvae tends to be associated with dispersal ability, although exceptions exist. Brooded larvae often settle soon after they are released which limits their ability to disperse (Nozawa \& Harrison, 2005; Sakai, 1997; Warner et al., 2016) and short competency periods in brooded larvae may be responsible for producing localized dispersal patterns observed in high-latitude communities (Tioho et al., 2001). In spawners, gametes may remain planktonic for several days, enhancing their potential for dispersal (Nozawa \& Harrison, 2008). The larvae of spawners A. millepora, A. tenuis, and M. digitata possess a high lipid content which makes them buoyant, enabling dispersal by wind and currents and provides energy storage during periods of extended dispersal (Arai et al., 1993; Richmond, 1987); however, this trait is not present in all spawners. Nevertheless, brooders exhibiting high connectivity across vertical gradients (Hammerman et al., 2018; Serrano et al., 2016) and spawners possessing strong vertical genetic partitioning have been documented (Eckert et al., 2019; Serrano et al., 2014).

The S1 and S3 periods (April-October) spanned the main coral spawning period at Ludao (Dai \& Fan, 1992; Nozawa et al., 2013). Most corals in Taiwan do not spawn during October-April, and observed patterns were consistent with expectations. Pocillopora dominance persisted during S1 and S3, but not during S2, when their abundance was comparable to other taxa. Kuo and Soong (2010) found variable pocilloporid recruitment during wet (May-September) and dry seasons (November to March) and observed similar patterns interannually. Fan et al. (2006) observed larval release in Stylophora pistillata and Pocillopora damicornis in Taiwan during winter months (February-March), providing the most likely explanation for the presence of these species. In Ludao, P. damicornis is uncommon while $P$. verrucosa is abundant (Y. Nozawa, personal communication). Recently, $P$. verrucosa has been found to brood in nearby Philippines (Villanueva et al., 2008) that wintertime P. verrucosa recruits could actually be brooded; however, further study is required. Several other pocilloporids can reproduce asexually, which could provide an alternative explanation for winter recruitment: Pocillopora acuta may generate planula asexually in the absence of sperm (Nakajima et al., 2018; Smith et al., 2019), and P. damicornis may produce clonal larvae, although this behavior may vary along latitudinal gradients (Miller \& Ayre, 2004). Additionally, clonal reproduction in this species may be undertaken in response to disturbances (Sherman et al., 2006; Yeoh \& Dai, 2010). Corals of the Montipora genus typically spawn between April and June in Taiwan, but may be subject to interannual variability (Lin \& Nozawa, 2017); the small spat size $(2.1 \mathrm{~mm})$ of the Montipora sp. (II) spat collected during S2 suggests it spawned late during this season, potentially explaining its retrieval during our winter survey. Lastly, it is possible that larvae with extended larval development released during the regular spawning season may remain viable to recruit during wintertime.

We emphasize the limitations in making inferences of the distribution of corals based on recruitment patterns; therefore, our 
conclusions warrant caution. Substrate choice is one of the most important factors determining the survival of coral larvae (RitsonWilliams et al., 2009) and larvae may select locations that maximize their chances of surviving (Martinez \& Abelson, 2013). We hypothesize that tile choice may influence results by providing a more favorable habitat to some while detracting others from settling. Indeed, Harriott and Fisk (1987) found the composition of acroporid and pocilloporid larvae settling on artificial substrates diverged from natural surfaces. Likewise, Burt et al. (2009) found recruitment densities varied among settlement substrate types. In some cases, diverging preferences may apply to close relatives: in azooxanthellate corals, Tubastraea tagusensis settles more densely on concrete substrates, while Tubastraea coccinea exhibits no such preference (Creed \& De Paula, 2007). In addition, the date of initiation of the experiment could bias results toward MOTUs with later spawning dates if settlement tiles have not accumulated sufficient biofilm to promote metamorphosis (Webster et al., 2004). However, uncured terra-cotta tiles do not have this effect on Acropora millepora larvae, indicating that some species are less selective than others (Heyward \& Negri, 1999).

Fluorescent censusing enhanced our ability to find recruits of small size. The application of fluorescence as an aid for recruit censusing was partly successful, but we observed variable intensity within MOTUs and between depths. It is well documented that not all coral species are fluorescent (Alieva et al., 2008; Gruber et al., 2008; Kenkel et al., 2011; Roth et al., 2015); however, a thorough registry of fluorescent corals does not exist. Additionally, in fluorescent types, intraspecific variation may occur (Eyal et al., 2015; Wangpraseurt et al., 2019). We were unable to quantitatively measure variation in fluorescence in our recruits, but we hypothesize that variation across shallow and deep light environments, in combination with differences in light exposure due to settlement location (i.e., vertical/horizontally oriented tile and top/bottom of the tile) could induce variation. The intensity of fluorescence may be influenced by light climates, such as depth (Scucchia et al., 2020) and shading surrounding the coral (Lesser \& Gorbunov, 2001; Ralph et al., 2002). Eyal et al. (2015) showed that fluorescent signals in some species are completely independent of light exposure, while in others, fluorescence may be lost in dark environments. Alternately, fluorescent signals may be impacted by coral health (Wangpraseurt, Larkum, et al., 2019) and dimmed fluorescent responses may indicate stress (Roth et al., 2015). Further study into interspecific and bathymetric variation in coral fluorescence during early-life stages is warranted.

Our AUR design resulted in a simple, affordable, and convenient tool to study recruitment. Tiles can be fixed to the block in advance and lowered into place by divers, forgoing drilling underwater to fix recruitment tiles directly to the substrate. This is advantageous in mesophotic settings where bottom time is limited and fieldwork is expensive; however, carrying heavy blocks at depth can be physically taxing on divers. Because the design is modular, scaling the quantity of blocks and tiles to tailor this method to individual requirements is feasible. This study fulfills a need for information on mesophotic recruitment and how it contrasts with shallow reefs.
These insights into local coral recruitment processes highlight the importance of early-life stage dynamics on mesophotic coral reef demographics. In few MOTUs recruiting abundantly across a wide depth distribution, our results are consistent with the mesophotic depth acting as a refuge for shallow-water communities. However, based on the evidence currently available, this tenet does not apply to most MOTUs which recruit scarcely and within their endemic depth range, warranting caution on generalizing this hypothesis at the community level. Nevertheless, connectivity over long timescales cannot be discredited and warrants further examination. More research is required to further expand our knowledge of recruitment and connectivity at depth, while delving into the physiological and environmental processes which affect them. As higher resolution molecular markers are developed, the resolution of molecular taxonomy will improve accordingly. Still, the present work represents a noteworthy improvement over traditional recruit identification. Future studies should strive to explore understudied geographical areas while developing innovative ways to overcome the challenges of surveying recruitment at depth.

\section{ACKNOWLEDGMENTS}

The authors would like to thank Dr. Rodrigo Carballo-Bolaños for assistance with fieldwork, Dr. Lauriane Ribas-Deulofeu for support with coding, and the personnel of the Green Island Marine Research Station and the Coral Reef Evolutionary Ecology and Genetics Laboratory at Academia Sinica for logistical assistance. We acknowledge Drs. James Reimer, Yoko Nozawa, and Nina Yasuda for insightful discussions on early versions of this manuscript. We appreciate the constructive commentary provided by Dr. Gal Eyal and an anonymous reviewer. We are grateful to the Taitung County Government for issuance of collection permits.

\section{CONFLICTS OF INTEREST}

The authors have no conflicts of interest to declare.

\section{AUTHOR CONTRIBUTION}

Derek Soto: Conceptualization (equal); Data curation (equal); Formal analysis (equal); Funding acquisition (equal); Investigation (equal); Methodology (equal); Resources (equal); Software (equal); Validation (equal); Visualization (equal); Writing-original draft (equal); Writingreview \& editing (equal). Stéphane De Palmas: Conceptualization (equal); Data curation (equal); Formal analysis (equal); Funding acquisition (equal); Investigation (equal); Methodology (equal); Validation (equal); Writing-original draft (equal); Writing-review \& editing (equal). Vianney Denis: Conceptualization (equal); Formal analysis (equal); Investigation (equal); Methodology (equal); Validation (equal); Writing-original draft (equal); Writing-review \& editing (equal). Ming-Jay Ho: Conceptualization (equal); Investigation (equal); Methodology (equal); Resources. Chaolun Allen Chen: Conceptualization (equal); Formal analysis (equal); Funding acquisition (equal); Investigation (equal); Methodology (equal); Project administration (equal); Resources; Software; Supervision (equal); Writing-original draft (equal); Writing-review \& editing (equal). 


\section{PERMITS}

Coral tissue samples were collected under Taitung County Government permit number 1040000285.

\section{DATA ACCESSIBILITY}

Coral recruit metadata and DNA sequences are publicly accessible on Dryad: https://doi.org/10.5061/dryad.msbcc2fz4.

\section{ORCID}

Derek Soto (iD https://orcid.org/0000-0002-5956-6223

Stéphane De Palmas (iD https://orcid.org/0000-0002-2567-1789

Vianney Denis (iD https://orcid.org/0000-0002-0914-5586

Chaolun Allen Chen (iD https://orcid.org/0000-0003-0452-4226

\section{REFERENCES}

Albelda, R. L., Cabaitan, P. C., Sinniger, F. P., Dumalagan Jr, E. E., Quimpo, T. J. R., Olavides, R. D. D., Munar, J. C., Villanoy, C. L., \& Siringan, F. P. (2020). Juvenile scleractinian assemblage and its association with adults and benthos at shallow and upper mesophotic depths in fringing and atoll reefs in the Philippines. Regional Studies in Marine Science, 40, 101514. https://doi.org/10.1016/j.rsma.2020.101514

Alieva, N. O., Konzen, K. A., Field, S. F., Meleshkevitch, E. A., Hunt, M. E., Beltran-Ramirez, V., Miller, D. J., Wiedenmann, J., Salih, A., \& Matz, M. V. (2008). Diversity and evolution of coral fluorescent proteins. PLoS One, 3, e2680. https://doi.org/10.1371/journ al.pone. 0002680

Altschul, S. F., Gish, W., Miller, W., Myers, E. W., \& Lipman, D. J. (1990). Basic local alignment search tool. Journal of Molecular Biology, 215, 403-410. https://doi.org/10.1016/S0022-2836(05)80360-2

Arai, I., Kato, M., Heyward, A., Ikeda, Y., lizuka, T., \& Maruyama, T. (1993). Lipid composition of positively buoyant eggs of reef building corals. Coral Reefs, 12, 71-75. https://doi.org/10.1007/BF00302104

Babcock, R. C., Baird, A. H., Piromvaragorn, S., Thomson, D. P., \& Willis, B. L. (2003). Identification of scleractinian coral recruits from IndoPacific reefs. Zoological Studies, 42, 211-226.

Bahr, K. D., Tran, T., Jury, C. P., \& Toonen, R. J. (2020). Abundance, size, and survival of recruits of the reef coral Pocillopora acuta under ocean warming and acidification. PLoS One, 15, e0228168.

Baird, A. H., \& Babcock, R. C. (2000). Morphological differences among three species of newly settled pocilloporid coral recruits. Coral Reefs, 19, 179-183. https://doi.org/10.1007/PL00006955

Baird, A. H., Madin, J. S., Álvarez-Noriega, M., Fontoura, L., Kerry, J. T., Kuo, C.-Y., Precoda, K., Torres-Pulliza, D., Woods, R. M., \& Zawada, K. J. A. (2018). A decline in bleaching suggests that depth can provide a refuge from global warming in most coral taxa. Marine Ecology Progress Series, 603, 257-264. https://doi.org/10.3354/ meps12732

Baird, A. H., Salih, A., \& Trevor-Jones, A. (2006). Fluorescence census techniques for the early detection of coral recruits. Coral Reefs, 25, 73-76. https://doi.org/10.1007/s00338-005-0072-7

Bak, R. P. M., \& Engel, M. S. (1979). Distribution, abundance and survival of juvenile hermatypic corals (Scleractinia) and the importance of life history strategies in the parent coral community. Marine Biology, 54, 341-352. https://doi.org/10.1007/BF00395440

Benson, D. A., Karsch-Mizrachi, I., Lipman, D. J., Ostell, J., \& Wheeler, D. L. (2005). GenBank. Nucleic Acids Research, 33, D34-D38. https:// doi.org/10.1093/nar/gki063

Birkeland, C. (1977). The importance of rate of biomass accumulation in early succession stages of benthic communities to the survival of coral recruits. Proceedings of the 3rd International Coral Reef Symposium (pp. 16-21).
Birkeland, C., Rowley, D., \& Randall, R. H. (1981). Coral recruitment patterns at Guam Proceedings of the 4th International Coral Reef Symposium (pp. 339-344).

Bongaerts, P., Ridgway, T., Sampayo, E. M., \& Hoegh-Guldberg, O. (2010). Assessing the 'Deep Reef Refugia' hypothesis: Focus on Caribbean reefs. Coral Reefs, 29, 309-327. https://doi.org/10.1007/s0033 8-009-0581-x

Bongaerts, P., Riginos, C., Brunner, R., Englebert, N., Smith, S. R., \& Hoegh-Guldberg, O. (2017). Deep reefs are not universal refuges: Reseeding potential varies among coral species. Science Advances, 3, e1602373. https://doi.org/10.1126/sciadv.1602373

Bongaerts, P., \& Smith, T. B. (2019). Beyond the "Deep Reef Refuge" hypothesis: A conceptual framework to characterize persistence at depth. In Y. Loya, K. Puglise, \& T. Bridge (Eds.), Mesophotic Coral Ecosystems (pp. 881-895). Springer. https://doi.org/10.1007/9783-319-92735-0_45

Brazeau, D. A., Lesser, M. P., \& Slattery, M. (2013). Genetic structure in the coral, Montastraea cavernosa: Assessing genetic differentiation among and within mesophotic reefs. PLoS One, 8, e65845.

Budd, A. F., \& Stolarski, J. (2011). Corallite wall and septal microstructure in scleractinian reef corals: Comparison of molecular clades within the family Faviidae. Journal of Morphology, 88, 66-88.

Burt, J., Bartholomew, A., Bauman, A., Saif, A., \& Sale, P. F. (2009). Coral recruitment and early benthic community development on several materials used in the construction of artificial reefs and breakwaters. Journal of Experimental Marine Biology and Ecology, 373, 72-78. https://doi.org/10.1016/j.jembe.2009.03.009

Chen, C., Chiou, C.-Y., Dai, C.-F., \& Chen, C. A. (2008). Unique mitogenomic features in the scleractinian family Pocilloporidae (Scleractinia: Astrocoeniina). Marine Biotechnology, 10, 538. https:// doi.org/10.1007/s10126-008-9093-x

Chen, C. A., \& Dai, C.-F. (2004). Local phase shift from Acropora-dominant to Condylactis-dominant community in the Tiao-Shi Reef, Kenting National Park, southern Taiwan. Coral Reefs, 23, 508. https://doi. org/10.1007/s00338-004-0423-9

Creed, J. C., \& De Paula, A. F. (2007). Substratum preference during recruitment of two invasive alien corals onto shallow-subtidal tropical rocky shores. Marine Ecology Progress Series, 330, 101-111. https:// doi.org/10.3354/meps330101

Dai, C.-F., \& Fan, T. Y. (1992). Sexual Reproduction of Corals in Northern and Southen Taiwan. Proceedings of the 7th International Coral Reef Symposium (pp. 448-455).

Dai, C.-F., \& Horng, S. (2009a). Scleractinia Fauna of Taiwan I: Complex Group. National Taiwan University Press.

Dai, C.-F., \& Horng, S. (2009b). Scleractinia Fauna of Taiwan II: Robust group. National Taiwan University Press.

Darling, E. S., Alvarez-Filip, L., Oliver, T. A., McClanahan, T. R., \& Côté, I. M. (2012). Evaluating life-history strategies of reef corals from species traits. Ecology Letters, 15, 1378-1386. https://doi. org/10.1111/j.1461-0248.2012.01861.x

de Palmas, S. (2020). Mesophotic Coral Ecosystems (MCEs) of Ludao: Potential refuge for future Taiwanese coral reefs? National Taiwan Normal University.

de Palmas, S., Soto, D., Denis, V., Ho, M.-J., \& Chen, C. A. (2018). Molecular assessment of Pocillopora verrucosa (Scleractinia; Pocilloporidae) distribution along a depth gradient in Ludao, Taiwan. Peer J, 6, e5797.

Denis, V., de Palmas, S., Benzoni, F., \& Chen, C. A. (2015). Extension of the known distribution and depth range of the scleractinian coral Psammocora stellata: First record from a Taiwanese mesophotic reef. Marine Biodiversity, 45, 619-620. https://doi.org/10.1007/ s12526-014-0299-z

Denis, V., Ribas-Deulofeu, L., Sturaro, N., Kuo, C.-Y., \& Chen, C. A. (2017). A functional approach to the structural complexity of coral assemblages based on colony morphological features. Scientific Reports, 7, 9849. https://doi.org/10.1038/s41598-017-10334-w 
Denis, V., Soto, D., de Palmas, S., Lin, Y. T. V., Benayahu, Y., Huang, Y. M., Liu, S.-L., Chen, J.-W., Chen, Q., Sturaro, N., Ho, M.-J., Su, Y., Dai, C. F., \& Chen, C. A. (2019). Taiwan. In Y. Loya, K. Puglise, \& T. Bridge (Eds.), Mesophotic Coral Ecosystems of the World (pp. 249264). Springer.

Eckert, R. J., Studivan, M. S., \& Voss, J. D. (2019). Populations of the coral species Montastraea cavernosa on the Belize Barrier Reef lack vertical connectivity. Scientific Reports, 9, 7200. https://doi. org/10.1038/s41598-019-43479-x

Edgar, R. C. (2004). MUSCLE: Multiple sequence alignment with high accuracy and high throughput. Nucleic Acids Research, 32, 1792-1797. https://doi.org/10.1093/nar/gkh340

Edmunds, P. J., Nozawa, Y., \& Villanueva, R. D. (2014). Refuges modulate coral recruitment in the Caribbean and the Pacific. Journal of Experimental Marine Biology and Ecology, 454, 78-84. https://doi. org/10.1016/j.jembe.2014.02.009

Eyal, G., Wiedenmann, J., Grinblat, M., D’Angelo, C., Kramarsky-Winter, E., Treibitz, T., Ben-Zvi, O., Shaked, Y., Smith, T. B., \& Harii, S. (2015). Spectral diversity and regulation of coral fluorescence in a mesophotic reef habitat in the Red Sea. PLoS One, 10, e0128697. https:// doi.org/10.1371/journal.pone.0128697

Eyal-Shaham, L., Eyal, G., Tamir, R., \& Loya, Y. (2016). Reproduction, abundance and survivorship of two Alveopora spp. in the mesophotic reefs of Eilat, Red Sea. Scientific Reports, 6, 20964. https:// doi.org/10.1038/srep20964

Fan, T.-Y., Lin, K.-H., Kuo, F.-W., Soong, K., Liu, L.-L., \& Fang, L.-S. (2006). Diel patterns of larval release by five brooding scleractinian corals. Marine Ecology Progress Series, 321, 133-142. https://doi. org $/ 10.3354 /$ meps321133

Felsenstein, J. (2004). PHYLIP (Phylogeny Inference Package) version 3.6. Distributed by the author.

Field, S. N., Glassom, D., \& Bythell, J. (2007). Effects of artificial settlement plate materials and methods of deployment on the sessile epibenthic community development in a tropical environment. Coral Reefs, 26, 279-289. https://doi.org/10.1007/s00338-006-0191-9

Folmer, O., Black, M., Hoeh, W., Lutz, R., \& Vrijenhoek, R. (1994). DNA primers for amplification of mitochondrial cytochrome $c$ oxidase subunit I from diverse metazoan invertebrates. Molecular Marine Biology and Biotechnology, 3, 294-299.

Gilis, M., Meibom, A., Domart-Coulon, I., Grauby, O., Stolarski, J., \& Baronnet, A. (2014). Biomineralization in newly settled recruits of the scleractinian coral Pocillopora damicornis. Journal of Morphology, $275,1349-1365$.

Green, D. H., \& Edmunds, P. J. (2011). Spatio-temporal variability of coral recruitment on shallow reefs in St. John, US Virgin Islands. Journal of Experimental Marine Biology and Ecology, 397, 220-229. https:// doi.org/10.1016/j.jembe.2010.12.004

Gruber, D. F., Kao, H.-T., Janoschka, S., Tsai, J., \& Pieribone, V. A. (2008). Patterns of fluorescent protein expression in scleractinian corals. The Biological Bulletin, 215, 143-154. https://doi. org/10.2307/25470695

Hammerman, N. M., Rivera-Vicens, R. E., Galaska, M. P., Weil, E., Appledoorn, R. S., Alfaro, M., \& Schizas, N. V. (2018). Population connectivity of the plating coral Agaricia lamarcki from southwest Puerto Rico. Coral Reefs, 37, 183-191. https://doi.org/10.1007/ s00338-017-1646-x

Harii, S., Kayanne, H., Takigawa, H., Hayashibara, T., \& Yamamoto, M. (2002). Larval survivorship, competency periods and settlement of two brooding corals, Heliopora coerulea and Pocillopora damicornis. Marine Biology, 141, 39-46. https://doi.org/10.1007/s0022 7-002-0812-y

Harrigan, J. F. (1972). Behavior of planula larva of scleractinian coral Pocillopora damicornis. American Zoologist, 12, 723.

Harriott, V. J., \& Fisk, D. A. (1987). A comparison of settlement plate types for experiments on the recruitment of scleractinian corals. Marine
Ecology Progress Series, 37, 201-208. https://doi.org/10.3354/ meps037201

Harrison, P. L. (2011). Sexual reproduction of scleractinian corals. In Coral reefs: an ecosystem in transition (pp. 59-85). Springer.

Hata, T., Madin, J. S., Cumbo, V. R., Denny, M., Figueiredo, J., Harii, S., Thomas, C. J., \& Baird, A. H. (2017). Coral larvae are poor swimmers and require fine-scale reef structure to settle. Scientific Reports, 7 , 1-9. https://doi.org/10.1038/s41598-017-02402-y

Heyward, A. J., \& Negri, A. P. (1999). Natural inducers for coral larval metamorphosis. Coral Reefs, 18, 273-279. https://doi.org/10.1007/ s003380050193

Hill, J., \& Wilkinson, C. (2004). Methods for ecological monitoring of coral reefs, Version 1 (pp. 1-117). Australian Institute of Marine Science.

Ho, M.-J., \& Dai, C.-F. (2014). Coral recruitment of a subtropical coral community at Yenliao Bay, northern Taiwan. Zoological Studies, 53,5 .

Hoegh-Guldberg, O., Kennedy, E. V., Beyer, H. L., McClennen, C., \& Possingham, H. P. (2018). Securing a long-term future for coral reefs. Trends in Ecology \& Evolution, 33, 936-944. https://doi. org/10.1016/j.tree.2018.09.006

Holstein, D. M., Smith, T. B., Gyory, J., \& Paris, C. B. (2015). Fertile fathoms: Deep reproductive refugia for threatened shallow corals. Scientific Reports, 5, 12407. https://doi.org/10.1038/srep12407

Holstein, D. M., Smith, T. B., \& Paris, C. B. (2016). Depth-independent reproduction in the reef coral Porites astreoides from shallow to mesophotic zones. PLoS One, 11, e0146068. https://doi.org/10.1371/ journal.pone.0146068

Hsu, C.-M., de Palmas, S., Kuo, C.-Y., Denis, V., \& Chen, C. A. (2014). Identification of scleractinian coral recruits using fluorescent censusing and DNA barcoding techniques. PLoS One, 9, e107366. https://doi.org/10.1371/journal.pone.0107366

Huang, D., Licuanan, W. Y., Hoeksema, B. W., Chen, C. A., Ang, P. O., Huang, H., Lane, D. J., Vo, S. T., Waheed, Z., Affendi, Y. A., \& Yeemin, T. (2015). Extraordinary diversity of reef corals in the South China Sea. Marine Biodiversity, 45(2), 157-168.

Hughes, T. P., Barnes, M. L., Bellwood, D. R., Cinner, J. E., Cumming, G. S., Jackson, J. B. C., Kleypas, J., Van De Leemput, I. A., Lough, J. M., \& Morrison, T. H. (2017). Coral reefs in the Anthropocene. Nature, 546, 82. https://doi.org/10.1038/nature22901

Hughes, T. P., \& Tanner, J. E. (2000). Recruitment failure, life histories, and long-term decline of Caribbean corals. Ecology, 81, 2250-2263.

Kahng, S. E., Akkaynak, D., Shlesinger, T., Hochberg, E. J., Wiedenmann, J., Tamir, R., \& Tchernov, D. (2019). Light, temperature, photosynthesis, heterotrophy, and the lower depth limits of mesophotic coral ecosystems. In Y. Loya, K. Puglise, \& T. Bridge (Eds.), Mesophotic Coral Ecosystems (pp. 801-828). Springer.

Kayal, M., Lenihan, H. S., Brooks, A. J., Holbrook, S. J., Schmitt, R. J., $\&$ Kendall, B. E. (2018). Predicting coral community recovery using multi-species population dynamics models. Ecology Letters, 21, 1790-1799. https://doi.org/10.1111/ele.13153

Kayal, M., Vercelloni, J., Wand, M. P., \& Adjeroud, M. (2015). Searching for the best bet in life-strategy: A quantitative approach to individual performance and population dynamics in reef-building corals. Ecological Complexity, 23, 73-84. https://doi.org/10.1016/j. ecocom.2015.07.003

Kenkel, C. D., Aglyamova, G., Alamaru, A., Bhagooli, R., Capper, R., Cunning, R., deVillers, A., Haslun, J. A., Hédouin, L., \& Keshavmurthy, S. (2011). Development of gene expression markers of acute heatlight stress in reef-building corals of the genus Porites. PLoS One, 6 , e26914. https://doi.org/10.1371/journal.pone.0026914

Kramer, N., Eyal, G., Tamir, R., \& Loya, Y. (2019). Upper mesophotic depths in the coral reefs of Eilat, Red Sea, offer suitable refuge grounds for coral settlement. Scientific Reports, 9, 2263.

Kuo, C.-Y., Meng, P.-J., Ho, P.-H., Wang, J.-T., Chen, J.-P., Chiu, Y.-W., Lin, H.-J., Chang, Y.-C., Fan, T.-Y., \& Chen, C. A. (2011). Damage to the 
reefs of Siangjiao Bay marine protected area of Kenting National Park, southern Taiwan during typhoon Morakot. Zoological Studies, $1,50$.

Kuo, C.-Y., Yuen, Y. S., Meng, P.-J., Ho, P.-H., Wang, J.-T., Liu, P.-J., Chang, Y.-C., Dai, C.-F., Fan, T.-Y., \& Lin, H.-J. (2012). Recurrent disturbances and the degradation of hard coral communities in Taiwan. PLoS One, 7, e44364. https://doi.org/10.1371/journal.pone.0044364

Kuo, K.-M., \& Soong, K. (2010). Post-settlement survival of reef-coral juveniles in southern Taiwan. Zoological Studies, 49, 724-734.

Lau, A. Y. A., Terry, J. P., Switzer, A. D., \& Pile, J. (2015). Advantages of beachrock slabs for interpreting high-energy wave transport: Evidence from Ludao Island in south-eastern Taiwan. Geomorphology, 228, 263-274. https://doi.org/10.1016/j.geomo rph.2014.09.010

Lesser, M. P., \& Gorbunov, M. Y. (2001). Diurnal and bathymetric changes in chlorophyll fluorescence yields of reef corals measured in situ with a fast repetition rate fluorometer. Marine Ecology Progress Series, 212, 69-77. https://doi.org/10.3354/meps212069

Letunic, I., \& Bork, P. (2019). Interactive Tree Of Life (iTOL) v4: Recent updates and new developments. Nucleic Acids Research, 47(W1), W256-W259. https://doi.org/10.1093/nar/gkz239

Lin, C.-H., \& Nozawa, Y. (2017). Variability of spawning time (lunar day) in Acropora versus merulinid corals: A 7-yr record of in situ coral spawning in Taiwan. Coral Reefs, 36, 1269-1278. https://doi. org/10.1007/s00338-017-1622-5

Lin, Y. V., \& Denis, V. (2019). Acknowledging differences: Number, characteristics, and distribution of marine benthic communities along Taiwan coast. Ecosphere, 10, e02803.

Madin, J. S. (2005). Mechanical limitations of reef corals during hydrodynamic disturbances. Coral Reefs, 24, 630-635. https://doi. org/10.1007/s00338-005-0042-0

Martinez, S., \& Abelson, A. (2013). Coral recruitment: The critical role of early post-settlement survival. ICES Journal of Marine Science, 70, 1294-1298. https://doi.org/10.1093/icesjms/fst035

Mayfield, A. B., Chen, Y.-J., Lu, C.-Y., \& Chen, C.-S. (2018). The proteomic response of the reef coral Pocillopora acuta to experimentally elevated temperatures. PLoS One, 13, e0192001. https://doi. org/10.1371/journal.pone.0192001

Miller, K. J., \& Ayre, D. J. (2004). The role of sexual and asexual reproduction in structuring high latitude populations of the reef coral Pocillopora damicornis. Heredity, 92, 557-568. https://doi. org/10.1038/sj.hdy.6800459

Mundy, C. N. (2000). An appraisal of methods used in coral recruitment studies. Coral Reefs, 19, 124-131. https://doi.org/10.1007/s003380000081

Nakajima, Y., Chuang, P.-S., Ueda, N., \& Mitarai, S. (2018). First evidence of asexual recruitment of Pocillopora acuta in Okinawa Island using genotypic identification. PeerJ, 6, e5915.

Noreen, A. M. E., Harrison, P. L., \& Van Oppen, M. J. H. (2009). Genetic diversity and connectivity in a brooding reef coral at the limit of its distribution. Proceedings of the Royal Society B: Biological Sciences, 276, 3927-3935. https://doi.org/10.1098/rspb.2009.1050

Nozawa, Y., \& Harrison, P. L. (2005). Temporal settlement patterns of larvae of the broadcast spawning reef coral Favites chinensis and the broadcast spawning and brooding reef coral Goniastrea aspera from Okinawa, Japan. Coral Reefs, 24, 274-282. https://doi.org/10.1007/ s00338-005-0476-4

Nozawa, Y., \& Harrison, P. L. (2008). Temporal patterns of larval settlement and survivorship of two broadcast-spawning acroporid corals. Marine Biology, 155, 347-351. https://doi.org/10.1007/s0022 7-008-1034-8

Nozawa, Y., Lin, C.-H., \& Chung, A.-C. (2013). Bathymetric variation in recruitment and relative importance of pre-and post-settlement processes in coral assemblages at Lyudao (Green Island), Taiwan. PLoS One, 8, e81474. https://doi.org/10.1371/journal.pone.0081474
O'Cain, E. D., Frischer, M. E., Harrison, J. S., Walters, T. L., Thompson, M. E., Fogarty, N. D., Ruzicka, R., \& Gleason, D. F. (2019). Identification of newly settled Caribbean coral recruits by ITS-targeted singlestep nested multiplex PCR. Coral Reefs, 38, 79-92. https://doi. org/10.1007/s00338-018-01763-8

Okonechnikov, K., Golosova, O., \& Fursov, M., \& U. Team (2012). Unipro UGENE: A unified bioinformatics toolkit. Bioinformatics, 28, 11661167. https://doi.org/10.1093/bioinformatics/bts091

Poquita-Du, R. C., Ng, C. S. L., Bin Loo, J., Afiq-Rosli, L., Tay, Y. C., Todd, P. A., Chou, L. M., \& Huang, D. (2017). New evidence shows that Pocillopora 'damicornis-like'corals in Singapore are actually Pocillopora acuta (Scleractinia: Pocilloporidae). Biodiversity Data Journal, 5, e11407. https://doi.org/10.3897/BDJ.5.e11407

Prasetia, R., Sinniger, F., \& Harii, S. (2016). Gametogenesis and fecundity of Acropora tenella (Brook 1892) in a mesophotic coral ecosystem in Okinawa, Japan. Coral Reefs, 35, 53-62. https://doi.org/10.1007/ s00338-015-1348-1

Prasetia, R., Sinniger, F., Hashizume, K., \& Harii, S. (2017). Reproductive biology of the deep brooding coral Seriatopora hystrix: Implications for shallow reef recovery. PLoS One, 12, e0177034. https://doi. org/10.1371/journal.pone.0177034

R Core Team (2013). R: A language and environment for statistical computing. Distributed by the author.

Ralph, P., Gademann, R., Larkum, A., \& Kühl, M. (2002). Spatial heterogeneity in active chlorophyll fluorescence and PSIl activity of coral tissues. Marine Biology, 141, 639-646. https://doi.org/10.1007/ s00227-002-0866-x

Ribas-Deulofeu, L., Denis, V., de Palmas, S., Kuo, C.-Y., Hsieh, H. J., \& Chen, C. A. (2016). Structure of benthic communities along the Taiwan latitudinal gradient. PLoS One, 11, e0160601. https://doi. org/10.1371/journal.pone.0160601

Richmond, R. H. (1987). Energetic relationships and biogeographical differences among fecundity, growth and reproduction in the reef coral Pocillopora damicornis. Bulletin of Marine Science, 41, 594-604.

Ritson-Williams, R., Arnold, S. N., Fogarty, N. D., Steneck, R. S., Vermeij, M. J. A., \& Paul, V. J. (2009). New perspectives on ecological mechanisms affecting coral recruitment on reefs. Smithsonian Contributions to the Marine Sciences, 38, 437. https://doi.org/10.5479/si.01960 768.38.437

Rogers, C. S., Fitz, H. C., Gilnack, M., Beets, J., \& Hardin, J. (1984). Scleractinian coral recruitment patterns at salt river submarine canyon, St. Croix, U. S. Virgin Islands. Coral Reefs, 3, 69-76. https://doi. org/10.1007/BF00263756

Roth, M. S., Fan, T.-Y., \& Deheyn, D. D. (2013). Life history changes in coral fluorescence and the effects of light intensity on larval physiology and settlement in Seriatopora hystrix. PLoS One, 8, e59476. https://doi.org/10.1371/journal.pone.0059476

Roth, M. S., Padilla-Gamiño, J. L., Pochon, X., Bidigare, R. R., Gates, R. D., Smith, C. M., \& Spalding, H. L. (2015). Fluorescent proteins in dominant mesophotic reef-building corals. Marine Ecology Progress Series, 521, 63-79. https://doi.org/10.3354/meps11108

Sakai, K. (1997). Gametogenesis, spawning, and planula brooding by the reef coral Goniastrea aspera (Scleractinia) in Okinawa, Japan. Marine Ecology Progress Series, 151, 67-72. https://doi.org/10.3354/meps1 51067

Schmidt-Roach, S., Miller, K. J., Lundgren, P., \& Andreakis, N. (2014). With eyes wide open: A revision of species within and closely related to the Pocillopora damicornis species complex (Scleractinia; Pocilloporidae) using morphology and genetics. Zoological Journal of the Linnean Society, 170, 1-33.

Scucchia, F., Nativ, H., Neder, M., Goodbody-Gringley, G., \& Mass, T. (2020). Physiological characteristics of Stylophora pistillata larvae across a depth gradient. Frontiers in Marine Science, 7, 13. https:// doi.org/10.3389/fmars.2020.00013 
Serrano, X. M., Baums, I. B., Oreilly, K., Smith, T. B., Jones, R. J., Shearer T. L., Nunes, F. L. D., \& Baker, A. C. (2014). Geographic differences in vertical connectivity in the Caribbean coral Montastraea cavernosa despite high levels of horizontal connectivity at shallow depths. Molecular Ecology, 23, 4226-4240.

Serrano, X. M., Baums, I. B., Smith, T. B., Jones, R. J., Shearer, T. L., \& Baker, A. C. (2016). Long distance dispersal and vertical gene flow in the Caribbean brooding coral Porites astreoides. Scientific Reports, 6, 21619. https://doi.org/10.1038/srep21619

Shanks, A. L. (2009). Pelagic larval duration and dispersal distance revisited. The Biological Bulletin, 216, 373-385. https://doi.org/10.1086/ BBLv216n3p373

Shanks, A. L., Grantham, B. A., \& Carr, M. H. (2003). Propagule dispersal distance and the size and spacing of marine reserves. Ecological Applications, 13, 159-169.

Sherman, C. D. H., Ayre, D. J., \& Miller, K. J. (2006). Asexual reproduction does not produce clonal populations of the brooding coral Pocillopora damicornis on the great barrier reef, Australia. Coral Reefs, 25, 7-18. https://doi.org/10.1007/s00338-005-0053-x

Shlesinger, T., Grinblat, M., Rapuano, H., Amit, T., \& Loya, Y. (2018). Can mesophotic reefs replenish shallow reefs? Reduced coral reproductive performance casts a doubt. Ecology, 99, 421-437. https://doi. org/10.1002/ecy.2098

Smith, H. A., Moya, A., Cantin, N. E., van Oppen, M. J. H., \& Torda, G. (2019). Observations of simultaneous sperm release and larval planulation suggest reproductive assurance in the coral Pocillopora acuta. Frontiers in Marine Science, 6, 362. https://doi.org/10.3389/ fmars.2019.00362

Smith, T. B., Brandtneris, V. W., Canals, M., Brandt, M. E., Martens, J., Brewer, R. S., Kadison, E., Kammann, M., Keller, J., \& Holstein, D. M. (2016). Potential structuring forces on a shelf edge upper mesophotic coral ecosystem in the US Virgin Islands. Frontiers in Marine Science, 3, 115. https://doi.org/10.3389/fmars.2016.00115

Soong, K., Chen, M.-H., Chen, C.-L., Dai, C.-F., Fan, T.-Y., Li, J.-J., Fan, H.M., Kuo, K.-M., \& Hsieh, H.-Y. (2003). Spatial and temporal variation of coral recruitment in Taiwan. Coral Reefs, 22, 224-228. https:// doi.org/10.1007/s00338-003-0311-8

Soto, D., de Palmas, S., Ho, M. J., Denis, V., \& Chen, C. A. (2018). Spatial variation in the morphological traits of Pocillopora verrucosa along a depth gradient in Taiwan. PLoS One, 13, e0202586. https://doi. org/10.1371/journal.pone.0202586

Szmant, A. M., \& Meadows, M. G. (2006). Developmental changes in coral larval buoyancy and vertical swimming behavior: Implications for dispersal and connectivity. Proceedings of the 10th International Coral Reef Symposium (pp. 431-437).

Tioho, H., Tokeshi, M., \& Nojima, S. (2001). Experimental analysis of recruitment in a scleractinian coral at high latitude. Marine Ecology Progress Series, 213, 79-86. https://doi.org/10.3354/meps213079

Turner, J. A., Babcock, R. C., Hovey, R., \& Kendrick, G. A. (2017). Deep thinking: A systematic review of mesophotic coral ecosystems. ICES Journal of Marine Science, 74, 2309-2320. https://doi.org/10.1093/ icesjms/fsx085

Turner, J. A., Thomson, D. P., Cresswell, A. K., Trapon, M., \& Babcock, R. C. (2018). Depth-related patterns in coral recruitment across a shallow to mesophotic gradient. Coral Reefs, 37, 711-722. https:// doi.org/10.1007/s00338-018-1696-8

Van Hooidonk, R., Maynard, J., Tamelander, J., Gove, J., Ahmadia, G., Raymundo, L., Williams, G., Heron, S. F., \& Planes, S. (2016).
Local-scale projections of coral reef futures and implications of the Paris Agreement. Scientific Reports, 6, 39666. https://doi. org/10.1038/srep39666

van Oppen, M. J. H., Bongaerts, P. I. M., Underwood, J. N., Peplow, L. M., $\&$ Cooper, T. F. (2011). The role of deep reefs in shallow reef recovery: An assessment of vertical connectivity in a brooding coral from west and east Australia. Molecular Ecology, 20, 1647-1660. https:// doi.org/10.1111/j.1365-294X.2011.05050.x

van Oppen, M. J. H., Lutz, A., De'ath, G., Peplow, L., \& Kininmonth, S. (2008). Genetic traces of recent long-distance dispersal in a predominantly self-recruiting coral. PLoS One, 3, e3401. https://doi. org/10.1371/journal.pone.0003401

Vaz, A. C., Paris, C. B., Olascoaga, M. J., Kourafalou, V. H., Kang, H., \& Reed, J. K. (2016). The perfect storm: Match-mismatch of biophysical events drives larval reef fish connectivity between Pulley Ridge mesophotic reef and the Florida Keys. Continental Shelf Research, 125, 136-146. https://doi.org/10.1016/j.csr.2016.06.012

Vermeij, M. J. A., Bakker, J., van der Hal, N., \& Bak, R. P. M. (2011). Juvenile coral abundance has decreased by more than $50 \%$ in only three decades on a small Caribbean island. Diversity, 3, 296-307. https://doi.org/10.3390/d3030296

Villanueva, R. D., Yap, H. T., \& Montano, M. N. E. (2008). Timing of planulation by pocilloporid corals in the northwestern Philippines. Marine Ecology Progress Series, 370, 111-119. https://doi.org/10.3354/ meps07659

Wangpraseurt, D., Larkum, A., Ferrier-Pagès, C., Salih, A., Warner, M. E., Hochberg, E. J., Dubinsky, Z., \& Kühl, M. (2019). Optics and Ecophysiology of Coral Reef Organisms. Frontiers in Marine Science, 6, 742 .

Wangpraseurt, D., Lichtenberg, M., Jacques, S. L., Larkum, A. W. D., \& Kühl, M. (2019). Optical properties of corals distort variable chlorophyll fluorescence measurements. Plant Physiology, 179, 16081619. https://doi.org/10.1104/pp.18.01275

Warner, P. A., Willis, B. L., \& van Oppen, M. J. H. (2016). Sperm dispersal distances estimated by parentage analysis in a brooding scleractinian coral. Molecular Ecology, 25, 1398-1415. https://doi. org/10.1111/mec.13553

Webster, N. S., Smith, L. D., Heyward, A. J., Watts, J. E. M., Webb, R. I., Blackall, L. L., \& Negri, A. P. (2004). Metamorphosis of a scleractinian coral in response to microbial biofilms. Applied and Environmental Microbiology, 70, 1213-1221. https://doi. org/10.1128/AEM.70.2.1213-1221.2004

Yeoh, S.-R., \& Dai, C.-F. (2010). The production of sexual and asexual larvae within single broods of the scleractinian coral, Pocillopora damicornis. Marine Biology, 157, 351-359. https://doi.org/10.1007/ s00227-009-1322-y

How to cite this article: Soto, D., De Palmas, S., Ho, M.-J., Denis, V., \& Allen Chen, C. (2021). A molecular census of early-life stage scleractinian corals in shallow and mesophotic zones. Ecology and Evolution, 11, 14573-14584. https://doi. org/10.1002/ece3.8122 